\title{
Total Complement Assay
}

National Cancer Institute

\section{Source}

National Cancer Institute. Total Complement Assay. NCI Thesaurus. Code C70617.

An assay to determine total complement levels as a measure of complement system activation. The complement system is a major component of innate immunity against microbes and a complement to humoral, antibody-triggered responses by the body. 